\title{
Review of Melvin Konner, Women After All: Sex, Evolution, and the End of Male Supremacy, New York: W.W. Norton, 2015
}

\author{
David Benatar $^{1}$
}

Published online: 8 August 2015

(C) Springer International Publishing 2015

Writing a critical book review is difficult for me. This is partly because I am mindful of the vast amount of work it takes to write a book, the serious scholarship it typically involves, and the fact that the author, at least in the case of academic books, is usually an intelligent person. Another reason why it is difficult is that that author is a person with feelings - and a negative review hurts.

Thus, let me state at the outset that Melvin Konner is a distinguished scholar with a vast command of anthropological, medical, and (evolutionary) psychology work on sex differences and related matters. He writes in an accessible way that can and probably will reach a fairly wide audience. There is thus much to admire in the author and in the book.

The book's chief failing, in my view, is in its central argument - that is, in the inferences it draws from the facts - and in the related interpretations of some of the facts.

The book's conclusion stated simply in its opening paragraph is that "women ... are superior to men in many ways, and in most ways that will count in the future" (p. 3). To this end, maleness is described as a "birth defect" that results in "shortened life span, higher mortality at all ages, an inability to reproduce, premature hair loss, and brain defects variously resulting in attention deficit, hyperactivity, conduct disorder,

David Benatar

philosophy@uct.ac.za

1 Department of Philosophy, University of Cape Town, Cape Town, South Africa hypersexuality, and an enormous excess of both outward and self-directed aggression" (p. 8). ${ }^{1}$

Professor Konner argues that mobile hunter-gatherer groups were marked by much less inequality between the sexes (p. 130) than became the case later. Women, he says, "had a voice; discussions were face-to-face, decisions day-today. Men tried to dominate them, but it wasn't easy" (p. 174). Inequalities increased, he says, when "hunter-gatherers settled in larger, denser populations" and became even more marked "with the rise of farming, again with the rise of chiefdoms, and yet again with the rise of empires" (Ibid).

He regards "male supremacy" as "a rather late development in human evolution" that will turn out to be temporary (p. 121). In some places, he describes it as having been maladaptive (p. 121) although elsewhere he says that it may once have had a purpose and perhaps "played some role in our success as a species so far" (p. 12). However, he is unequivocal that "now it is an obstacle" (p. 12).

In the future, he says, women will be equal or even dominant. For example, in developed countries, more females than males are graduating from high school and entering and graduating from tertiary educational institutions. Males are dropping out in greater numbers. In the current century and especially since the 2008 recession, men have been losing jobs at greater rates than women and male unemployment rates are much higher (p. 275). Professor Konner points to the many ways in which women have advanced - the increase in the number of female soldiers, political leaders, CEOs, and Nobel Prize winners. He regards this trajectory as "unstoppable" (pp. 5, 257).

\footnotetext{
${ }^{1}$ I cannot resist the subversive "anti-natalist" observation that when Professor Konner describes maleness as a "birth defect" he is only half right. Every birth - whether male, female, or in between - is a "defect" in the sense that it results in myriad sufferings before inevitable death.
} 
Professor Konner argues that the world will be better when female superiority has been (or allowed to be) fully expressed. For example, more female political leaders, he says, will mean less war because "all wars are boyish" (p. 213). It will also mean less sexual abuse and indiscretion by political leaders (pp. 267-270). There will also be less corruption and criminality among politicians (pp. 270-271) and in the corporate world (pp. 290-291), because although women are capable of corruption, they are, according to evidence he cites, less prone to it.

Professor Konner says that his book "will have something to offend almost everyone." For example, he says that "the idea that women are superior to men will offend a lot of men and some very good people of both sexes who are at present (rightly) worried about boys" (p. 17).

"Offence" does not capture my objection to this and related ideas in Women After All. (Quite frankly, I am baffled by the widespread contemporary invocation of "offence," which fills the place that charges of "heresy" once did in more religious times - and still do in some places.) Instead, I think that the idea is a misguided over-simplification.

Consider first Professor Konner's suggestion that females are superior to males in many ways. His justification for this is partly the fact that there are many biological disadvantages of being male and corresponding benefits to being female. The inference from biological advantage to superiority, if consistently applied, would imply that able-bodied, healthy people are superior to the disabled and sick. When this implication is recognized, we quickly notice the unfortunate ambiguity in "superior." Given this ambiguity, one can easily slip from thinking that some attributes are better than others - for example, being healthy is better than being sick - to thinking that some people are worth more than others or occupy a higher rung on some hierarchy. That is the very mistake that male supremacists have historically made in thinking about the relative status of men and women-although they thought that men were better than women.

There certainly are many biological disadvantages to being male. However, there are also quite a few biological disadvantages to being female. Menstruation is one example (except in cases of haemochromatosis), but so is the end of that cyclemenopause, which heralds another set of problems. Professor Konner says that males are unable to reproduce. It would be more accurate to say that they require a greater contribution from a female in order to procreate. If that is a biological disadvantage then it needs to be weighed against the female disadvantage of losing fertility much earlier than males. Moreover, in the absence of adequate obstetric care, women face non-negligible risks of peripartum morbidity and mortality.

The appropriate response to such disadvantages of being female is not to hail males as "superior" (in these ways) but to compensate for the natural disadvantage where we can (such as providing better obstetric care) and to sympathize with the disadvantaged where we cannot. In Women After All, there is only sporadic evidence of such remedial and compassionate responses to male disadvantage, yet there is much vaunting of female "superiority."

To be fair, one reason why Professor Konner thinks that women are superior is because they are more cooperative, less aggressive, and less motivated (and distracted) by sex. If these are desirable character traits or moral attributes, then perhaps the claim that they are "superior" (in these ways) is warranted.

The question, however, is whether a group of people who, on average, are more cooperative, less aggressive and less driven by sex, would rise in the same proportions to positions of leadership in domains where the opposite attributes may (very unfortunately) be necessary for success. If that is the case, then female dominance may not be the inevitable result Professor Konner predicts.

If, by contrast, female equality or dominance is not only inevitable but also as imminent as Professor Konner seems to think, then no affirmative action is necessary to facilitate the inevitable rise to ascendency. There is no need, for example, for Norway to have "mandated a quota of 40 percent women on every board" of directors of public companies (p. 287) or for the European Union parliament to have required a similar quota throughout the EU by 2020 (p. 288).

Similarly, Professor Konner repeatedly notes that males are more prone to brain defects, but he fails to consider the hypothesis that this might be one feature of different average distributions of mental attributes between the sexes. According to this fuller hypothesis, male mental ability may be overrepresented at both the bottom and the top because it has a flatter distribution than it does among females.

This hypothesis is, of course, the one that landed Lawrence Summers in so much trouble. Professor Konner joins the chorus of those who have misquoted Professor Summers. The latter never claimed that "women might not have the same abilities in math and science as the best men" (p. 265). Instead, he said that there might be more men than women at the top end - a subtly but importantly different claim.

It is curious that Professor Konner is happy to accept that more males than females are found at the bottom end but will not even consider the possibility that there might be more males than females at the top end. Lawrence Summers never claimed that the hypothesis is true - and nor am I-but only that it is worth considering and investigating.

If the heights of human achievement, at least in certain areas, would be disproportionately — note, not exclusively - male after all discriminatory obstacles to equality were removed then the fact that most violence and other crime is also male, would complicate simplistic judgments about which sex is "superior" on average. Indeed, it is interesting that when males are found in disproportionately large numbers in prisons, people like Professor Konner seem to assume that this has nothing to do with discrimination against males-males are just inferior in this way_-but when males are found in disproportionately large numbers in desirable social positions, it is assumed that this 
has (almost?) everything to do with discrimination against females. The truth is likely to be more complicated.

Professor Konner's projections of female equality and dominance may be unduly optimistic in another way. Although girls and women are doing remarkably well in the developed world, they are faring much worse in other parts of the world. Perhaps, it is just a matter of time before women in Afghanistan, Iran, and Saudi Arabia, for example, will gain equality, but there is nothing inevitable or "unstoppable" about it. Anybody interested in equality should be concerned about that in just the same way that they should be concerned about the ways in which males are worse off.

Peppered throughout Women After All are humorous jibes about (human and non-human) males. Some examples: "Perhaps it would take a man to miss the downside of sex" (p. 49); addressing females, he says that the male is "a member of your species, sort of" (p. 53); "She [the female praying mantis] can start by biting off his [the male mantis's] head while he is at it [that is, sex], and (typical male) his decapitated body can go right on with the show" (p. 55); "bonobo females are not exactly dominant over males, but they can make alliances themselves that give any would-be uppity male long pause before trying to dominate them" (p. 113); "while many of their male colleagues [in the US Senate] crossed their arms and sulked, women from opposite sides of the aisle phoned and e-mailed each other nonstop" (p. 282) (emphases mine).

These are all cutely humorous and I have no (moral) objection to them in their own right, but one does wonder what the reaction would be to a book in which such digs were made, mutatis mutandis, only about females. It would likely be labeled as a "sexist gaffe" (p. 277), a phrase Melvin Konner uses with reference to Lawrence Summers' hypothesizing mentioned earlier. Such a book's author would endure the sort of ostracism that Professor Summers did. Nor can Professor Konner defend exclusive anti-male humor by arguing that it is acceptable to mock those who are on top-because by his own account, males are inferior and women are rapidly becoming dominant.

For all its virtues, when it comes to differences between the sexes, Women After All is, after all, not impartial. 